\title{
Outbreak of Leaf Spot and Fruit Rot in Florida Strawberry Caused by Neopestalotiopsis spp.
}

\author{
Juliana S. Baggio, ${ }^{1}$ Bruna B. Forcelini, ${ }^{2}$ Nan-Yi Wang, ${ }^{1}$ Rafaela G. Ruschel, ${ }^{3}$ James C. Mertely, ${ }^{1}$ and Natalia A. Peres ${ }^{1, \dagger}$ \\ ${ }^{1}$ Gulf Coast Research and Education Center, University of Florida, Wimauma, FL 33598, U.S.A. \\ ${ }^{2}$ Corteva Agriscience, Indianapolis, IN 46268, U.S.A. \\ ${ }^{3}$ São Paulo State University, College of Agricultural Sciences, Botucatu, São Paulo 18610-034, Brazil
}

\begin{abstract}
Pestalotiopsis-like species have been reported affecting strawberry worldwide. Recently, severe and unprecedented outbreaks have been reported in Florida commercial fields where leaf, fruit, petiole, crown, and root symptoms were observed, and yield was severely affected. The taxonomic status of the fungus is confusing because it has gone through multiple reclassifications over the years. Morphological characteristics, phylogenetic analyses, and pathogenicity tests were evaluated for strawberry isolates recovered from diseased plants in Florida. Phylogenetic analyses derived from the combined internal transcribed spacer, $\beta$-tub, and tefl regions demonstrated that although there was low genetic diversity among the strawberry isolates, there was a clear separation of the isolates in

Most isolates recovered during the recent outbreaks were genetically different and may belong to a new species. On potato dextrose agar, both groups produced white, circular, and cottony colonies. From the bottom, colonies were white to pale yellow for Neopestalotiopsis sp. and pale luteous to orange for N. rosae. Spores for both groups were five-celled with three median versicolored cells. Mycelial growth and spore production were higher for the new Neopestalotiopsis sp. isolates. Isolates from both groups were pathogenic to strawberry roots and crowns. However, the new Neopestalotiopsis sp. proved more aggressive in fruit and leaf inoculation tests, confirming observations from the recent outbreaks in commercial strawberry fields in Florida.
\end{abstract} two groups. The first group included isolates recovered over a period of several years, which was identified as Neopestalotiopsis rosae.
Keywords: epidemiology, fungi, small fruits
The United States is the second largest producer of strawberry (Fragaria $\times$ ananassa Duch.) in the world with a total production of 1.3 million tons across 20,000 ha in 2018 (FAOSTAT 2020). California is the largest producer of strawberries in the United States, followed by Florida, which is the largest winter producer in the world. In Florida, strawberry plants are usually acquired from nurseries located in the northern United States, California, and Canada and transplanted in late September to mid-October on plastic-mulched raised beds. Fruit production occurs from November to March (Brown 2003; Whitaker et al. 2019).

Strawberry belongs to the family Rosaceae and is affected by numerous pathogens, especially fungi, causing severe disease and crop losses at different production stages, from nursery to postharvest. Among these pathogens, Pestalotiopsis longisetula (Pestalotia longisetula) was first reported causing strawberry fruit rot in Florida in 1972, with serious losses in some research plots and commercial fields (Howard and Albregts 1973). Subsequently, the pathogen has been described causing root and crown rots in Florida, as well as in Argentina, Bangladesh, Belgium, Egypt, Mexico, and Spain (Ara et al. 2017; Chamorro et al. 2016; Essa et al. 2018; Mertely et al. 2015; Obregón et al. 2018; Van Hemelrijck et al. 2017).

${ }^{\dagger}$ Corresponding author: N. A. Peres; nperes@ufl.edu

Funding: This work was partially supported by the Florida Strawberry Research and Education Foundation (FSREF).

*The $\boldsymbol{e}$-Xtra logo stands for "electronic extra" and indicates there are supplementary figures published online.

The author(s) declare no conflict of interest.

Accepted for publication 5 August 2020.

(C) 2021 The American Phytopathological Society
During the 2012-2013 Florida strawberry season, Pestalotiopsis spp. were repeatedly isolated from brown necrotic areas in crowns and roots of weak and stunted transplants (Mertely et al. 2015). Belowground symptoms were characterized by darkening of the roots and orange-brown necrosis in the crowns, which contributed to stunting or poor establishment after transplanting. Aboveground symptoms ranged from stunting to wilting and necrosis of older leaves, to eventual collapse and death of the entire plant. Similar symptoms were reported in Spain and Belgium (Chamorro et al. 2016; Van Hemelrijck et al. 2017). In some cases, Pestalotiopsis sp. is isolated along with other root and crown pathogens such as Colletotrichum spp., Phytophthora cactorum, and Macrophomina phaseolina. Hence, the fungus has always been considered a secondary pathogen, a weak and opportunistic pathogen that has never been of major concern in the strawberry industry.

However, in 2017 a Pestalotiopsis-like fungus was identified from spotted fruit and leaves in a commercial field near Dover, Florida (Fig. 1). Another outbreak of leaf spot and fruit rot occurred across three commercial fields in 2018. In one case, a grower was forced to destroy 35 ha midseason and stopped harvesting another 15 ha before the season ended. Another grower elected not to harvest an 8-ha block because of fruit spotting and weak plant growth caused by loss of infected leaves. A more severe outbreak happened in the 2019-2020 season, affecting about 18 commercial farms. Symptoms were more severe in organic production fields, and some growers have reported destroying the most affected parts of their fields to avoid pathogen dissemination and contamination of other areas. It is estimated that at least 80 ha of strawberry fields was destroyed. Most of the commercial strawberry cultivars grown in Florida were affected by the disease, and the common link between these outbreaks was the nursery source for the plants. Fruit and leaf symptoms caused by Pestalotiopsis sp. have also been reported in other strawberry-producing areas such as Brazil, China, Egypt, India, Iran, Israel, Mexico, and Morocco (Ayoubi and Soleimani 2016; Camili et al. 2002; Embaby 2007; Kenneth et al. 1968; Mahapatra et al. 2018; Mouden et al. 2014; Rebollar-Alviter et al. 2020; Zhao 2016). 
Symptoms on strawberry fruit are lesions 2 to $4 \mathrm{~mm}$ in diameter, dry, light tan, slightly sunken, and irregular in shape in the early stages (Fig. 1A). Lesions grow and eventually are covered by numerous acervuli oozing shiny black droplets of matricial liquid containing spores (Fig. 1B). Under humid conditions, dense white mycelium may also form on the lesion. Eventually, the entire fruit is affected and mummified (Howard and Albregts 1973; Kenneth et al. 1968; Maas 1998). On leaves, light to dark brown spots of different sizes are irregularly distributed (Fig. 1C), and in more advanced stages, black acervuli can develop in older necrotic tissue (Fig. 1D; Ayoubi and Soleimani 2016; Rodrigues et al. 2014). In recent outbreaks in Florida, mass spotting often produced blight-like necrosis of broad areas of the lamella, eventually killing the leaf. The fungus produces spores on the surface of infected tissues that are dispersed by water, and disease outbreaks are favored during periods of heavy rains and warm temperatures. When conditions are highly conducive to disease development and plants are severely affected, the disease also contributes to poor development of the plants, which become stunted and produce small leaves (Fig. 1E).

Pestalotiopsis is an asexual genus in the family Sporocadaceae (Liu et al. 2019) and is common in tropical and temperate areas. Various species cause leaf blights or spots, shoot dieback, fruit rots, and postharvest diseases on a wide range of hosts (Maharachchikumbura et al. 2012; Xu et al. 1999). They can also be isolated as endophytes or occur as saprobes and are known to produce a broad range of important secondary metabolites (Maharachchikumbura et al. 2011).

In strawberry, the fungus was originally reported as Pestalotia longisetula (Howard and Albregts 1973; Kenneth et al. 1968), following the description of Guba (1961), who isolated the fungus from canes of Rosa sp. Guba (1961) divided Pestalotia into three groups with species having four-, five-, or six-celled spores. However, Steyaert $(1949,1955)$ separated Pestalotia into three genera: Truncatella, Pestalotiopsis, and Pestalotia, accommodating species with four-, five-, and six-celled spores, respectively. Morphological characteristics, especially spore morphology, were considered to be stable characters for the classification of these fungi, which have been organized in genera according to the concolorous and versicolorous color patterns of median cells in the spores (Guba 1961; Jeewon et al. 2003; Steyaert 1949). Recent morphological analysis and molecular taxonomic techniques have resulted in the reclassification of Pestalotiopsis species into three major clades: Neopestalotiopsis, Pestalotiopsis, and Pseudopestalotiopsis (Maharachchikumbura et al. 2014). Species presenting versicolorous median cells were grouped in the genus Neopestalotiopsis, and several Pestalotiopsis species were transferred to this genus (Maharachchikumbura et al. 2014). Pestalotiopsis and Pseudopestalotiopsis are distinguished from each other by sequence data and the generally darker-colored concolorous median cells of the latter (Maharachchikumbura et al. 2014).

Because of the recent and unprecedented outbreaks caused by Pestalotiopsis-like fungi in Florida and the severe impact the disease has had on the strawberry industry, our objective was to study the morphological, molecular, and pathogenic characteristics of the pathogen.

\section{Materials and Methods}

Fungal isolates. Between 1997 and 2020, 67 Pestalotiopsis-like isolates from Florida strawberry production fields were collected from commercial farms or from samples submitted to the University of Florida's Gulf Coast Research and Education Center (UF GCREC) diagnostic clinic. In addition, 10 Pestalotiopsis-like isolates were collected from other hosts (two from Smilax sp., two from Quercus sp., four from Rhododendron sp., one from Limonium sp., and one from Kalmia sp.). Fungi were isolated from symptomatic lesions by direct transfer of spores from lesions or pieces of tissues disinfested with sodium hypochlorite and ethanol and plated on general isolation medium ( $12 \mathrm{~g} /$ liter of potato dextrose broth and $17 \mathrm{~g} / \mathrm{liter}$ of agar amended with streptomycin at $0.1 \mathrm{~g} /$ liter and ampicillin at 0.25 $\mathrm{g} /$ liter). Single-spore isolates were transferred to potato dextrose agar (PDA) and stored on filter paper or in glycerol at -20 and $-80^{\circ} \mathrm{C}$, respectively.
Molecular characterization. Sixty-seven isolates from strawberry and 10 from other hosts were grown on PDA for 7 days. Mycelium and spores were harvested to extract genomic DNA by using a DNA isolation kit according to the manufacturer's protocol. DNA of a Pestalotia longisetula strawberry isolate from Israel (CBS 638.68), considered a representative specimen of the pathogen in strawberry, was acquired from the culture collection of the Westerdijk Fungal Biodiversity Institute, Utrecht, in the Netherlands, and included in this study.

The partial internal transcribed spacer (ITS), $\beta$-tubulin $(\beta$-tub), and elongation factor (tefl) regions were amplified with PCR assays. The ITS, $\beta$-tub, and tefl regions were amplified with primers ITS 1 and ITS 4 described by White et al. (1990), Bt2a and Bt2b by Glass and Donaldson (1995), and EF1-526F and EF1-1567R by Rehner (2001), respectively. PCR mixtures contained $2 \mathrm{mM}$ of $\mathrm{MgCl}_{2}$, $200 \mu \mathrm{M}$ dNTP, $0.5 \mu \mathrm{M}$ of each primer, and 1.5 units of Taq polymerase (GoTaq G2 Hot Start Polymerase, Promega Corp.). For the ITS region, reactions were programmed with an initial denaturation at $94^{\circ} \mathrm{C}$ for $4 \mathrm{~min}$, followed by 35 cycles of $94^{\circ} \mathrm{C}$ for $45 \mathrm{~s}, 52^{\circ} \mathrm{C}$ for $45 \mathrm{~s}$, and $72^{\circ} \mathrm{C}$ for $1 \mathrm{~min}$, and a final extension of $72^{\circ} \mathrm{C}$ for $5 \mathrm{~min}$. For the $\beta$-tub and tefl genes, PCRs were performed under the same conditions, except for the annealing temperatures of 57 and $53^{\circ} \mathrm{C}$, respectively, and 30 cycles were used. PCR products were visualized under UV light in a $1 \%$ agarose gel in $1 \times$ Tris-acetate-EDTA buffer stained with GelRed ${ }^{\mathrm{TM}}$ (Biotium) and sent for purification and sequencing in both directions at Genewiz Inc. Sequences generated in this study were compared with those obtained from the NCBI GenBank database based on BLASTn searches and literature (Ayoubi and Soleimani 2016; Chamorro et al. 2016; Maharachchikumbura et al. 2014). Nucleotide sequences of the three regions (ITS, $\beta$-tub, and tefl) were assembled in Geneious (version 11.1.4), and multiple sequence alignments were generated with MAFFT version 7.309 (Katoh et al. 2002, Katoh and Standley 2013). Because of the sequence similarity within the same group of isolates, sequences of ITS, $\beta$-tub, and tefl regions of representative isolates 97-49F, 14$691 \mathrm{R}, 16-337 \mathrm{C}$, and $17-43 \mathrm{~L}$ were deposited in the GenBank (Table 1).

Given the possibility that each gene might be shaped by different evolutionary events, the dataset was examined for congruence via the partition homogeneity test (equivalent to the incongruence length difference test) implemented in PAUP* version 4.0a167 (Farris et al. 1994; Swofford 2003). The test was performed with 1,000 sample replicates and a heuristic maximum parsimony search with 100 replicates under random addition sequence and subtree pruning and regrafting branch swapping.

Subsequently, partitioned and unpartitioned maximum likelihood and Bayesian inference analyses of the combined regions were conducted in MrBayes version 3.2.7 (Ronquist et al. 2012) and GARLI version 2.01 (Bazinet et al. 2014), respectively. The best-fit substitution model was determined for each partition, and the combined, unpartitioned dataset using the automated model selection function implemented in PAUP* and selected based on the corrected Akaike information criterion scores as follows: general time reversible $(\mathrm{GTR})+\mathrm{G}$ ( $\gamma$ distribution, four categories) for ITS and tefl, K80 (Kimura two-parameter) $+\mathrm{G}$ for $\beta$-tub, and GTR $+\mathrm{G}+\mathrm{I}$ (invariable sites) for the combined dataset. Maximum likelihood analyses were run with default settings, except for the maximum program memory usage (availablememory $=10,000$ ), the number of generations without topology improvement required for termination (genthreshfortopoterm $=20,000$ ), and the maximum number of generations to run and maximum search time (stopgen $=5,000,000$, stoptime $=$ $5,000,000$ ). A total of 20 independent searches were performed, 10 starting from stepwise addition trees (streefname $=$ stepwise, searchreps $=10$ ) and 10 from randomly generated trees (streefname = random). The exhaustiveness of the global search was evaluated by comparison of the final maximum likelihood values between the 20 independent searches. Topology support was evaluated via 100 bootstrap replicates (bootstrapreps $=100$ ) under the same parameters for finding the best tree. Bayesian inference analyses were run with the same substitution model for 1 million generations, with sampling 
every 1,000 generations. Each analysis consisted of four independent runs, each using four coupled Markov chain Monte Carlo chains. The run convergence was monitored by finding the plateau in the likelihood scores (standard deviation of split frequencies $<0.01$ ). The first $25 \mathrm{f}$ of each run was discarded as burn-in for the estimation of a majority rule consensus topology and posterior probability for each node. Trees were visualized, edited, and rooted in FigTree version 1.4.2. (Rambaut and Drummond 2012). Trees included reference sequences from nine, three, and two Neopestalotiopsis spp. published by Maharachchikumbura et al. (2014), Ayoubi and Soleimani (2016), and Rebollar-Alviter et al. (2020), respectively, and one from Chamorro et al. (2016), A. L. Dann et al. (unpublished), and Essa et al. (2018) (Table 1). Two Pseudopestalotiopsis spp. and two Pestalotiopsis spp. published by Maharachchikumbura et al. (2014) were also used (Table 1).

Morphological characterization. Colony and spore characterization. Twenty isolates (Table 2) were revived from the UF GCREC culture collection on PDA (Difco ${ }^{\mathrm{TM}}$ and Oxoid), according to Maharachchikumbura et al. (2014), and incubated for 7 days at $24^{\circ} \mathrm{C}$ with a 12 -h photoperiod. Cultures were observed for colony color and shape, spore color, shape, length and width, and number and length of apical and basal appendages. Spore suspensions of each isolate were prepared in sterile deionized water, and spore measurements were determined by arbitrarily selecting 30 spores observed by using an Olympus BX41 microscope (Olympus America, Center Valley, PA) coupled to a camera and a computer, with OMAX ToupView (ToupTek, Zhejiang, China) software.

Mycelial growth at different temperatures. A mycelial plug (5-mm diameter) was taken from the edge of a 4- to 7-day-old actively growing colony of each isolate and placed upside down in the center of three replicates of $10-\mathrm{cm}$ diameter Petri dishes containing PDA. The effect of temperatures on mycelial growth was evaluated after 7 days of incubation at $5,10,15,20,25,30$, and $35^{\circ} \mathrm{C}$, with a 12 $\mathrm{h}$ photoperiod, by measuring colony diameter in two perpendicular directions and discounting $5 \mathrm{~mm}$ of the mycelial plug (average colony diameter). Two assays, with two experiments each, were conducted in two different periods. The first assay was performed in June 2018 with 10 isolates collected from 1997 to 2017 (Table 2). The second assay was conducted in March 2020 with two isolates from the first assay and 10 isolates collected during the 2018-2019 and 2019-2020 outbreaks (Table 2).

Spore production at different temperatures. Spore production was quantified for the aforementioned isolates 7 days after isolates were transferred to PDA and incubated at $5,10,15,20,25,30$, and $35^{\circ} \mathrm{C}$ with a 12-h photoperiod. Two assays were performed, with two experiments each. Sterile deionized water $(3 \mathrm{ml})$ was added to the plates containing the pathogen cultures. Structures were scraped with a flame-sterilized glass rod, and a 1-ml suspension was recovered. Spores were counted with a hemocytometer, and data were expressed as the number of spores per milliliter. In the first assay, performed in June 2018, spores of five isolates were quantified, whereas in the second assay, conducted in March 2020, spores of the 12 isolates characterized in the second mycelial growth assay were counted (Table 2).

Pathogenicity tests. Fruit inoculation. Pathogenicity of strawberry isolates was evaluated in two fruit assays, with two experiments each. The first assay was performed in March 2017 with nine isolates collected from 1997 to 2017 (Table 2). The second assay was
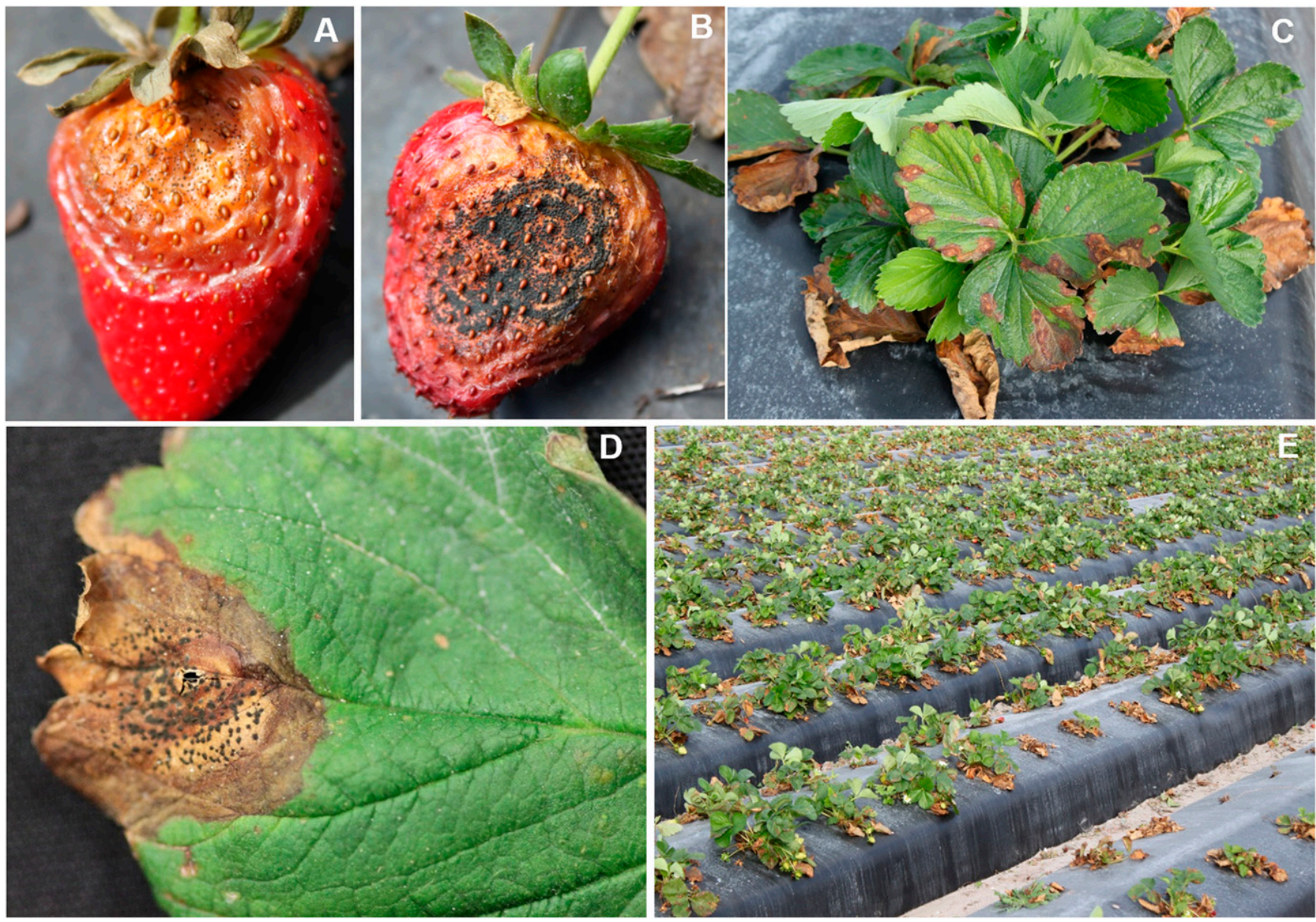

Fig. 1. Disease outbreak in Florida strawberry fields caused by the new Neopestalotiopsis sp. A, Early stage symptoms on ripe fruit; B, late stage symptoms on ripe fruit containing black acervuli of the pathogen; $\mathbf{C}$, light to dark brown spots of different sizes developing from the margins or from the tips of the leaves; $\mathbf{D}$, detail of leaf spots containing signs of the fungus; and $\mathbf{E}$, overall symptoms in the field with the presence of stunted plants and symptomatic leaves. 
conducted in March 2020 with three isolates from the first assay and eight isolates collected during the 2018-2019 and 2019-2020 outbreaks (Table 2). Strawberry fruits (Sensation 'Florida127') were harvested before commercial maturity (white-pink stage) from experimental plots at UF GCREC; sepals were removed, and the fruits were washed in $0.05 \%$ sodium hypochlorite for $2 \mathrm{~min}$ and rinsed twice in deionized water. Six nonwounded strawberry fruits per isolate were placed in egg trays, inoculated with $40 \mu \mathrm{l}$ of a spore suspension $\left(10^{4}\right.$ spores $\left./ \mathrm{ml}\right)$ and incubated at $24^{\circ} \mathrm{C}\left( \pm 2^{\circ} \mathrm{C}\right)$ under light in sealed plastic boxes containing water, serving as humidity chambers. Spore suspensions were obtained from 7- to 10-day-old colonies grown on PDA. In control treatments, $40 \mu$ l of water was placed on strawberry fruit. Disease incidence (percentage of symptomatic fruit based on total inoculated) was assessed 7 days after inoculation. Three replicate boxes were used per isolate, and the experiments were conducted twice for each assay.

Leaf inoculation. Pathogenicity of 13 strawberry isolates was evaluated in plant assays in growth room experiments (Table 2). Six cuttop, bare-root transplants of Sensation 'Florida127' per isolate were transplanted into 1-liter plastic pots filled with potting soil (MetroMix 820, Sun Gro Horticulture, Agawam, MA) in a greenhouse. Plants were overhead irrigated during daylight hours for 7 days, then irrigated twice daily through drip irrigation for 21 days to increase plant establishment. Afterward, plants were transferred to a growth room, and leaves were inoculated with an atomizer by spraying each plant with 5 to $10 \mathrm{ml}$ of spore suspensions of each isolate $\left(10^{4}\right.$ spores $\left./ \mathrm{ml}\right)$,

Table 1. Details of isolates from Florida strawberry and the reference species used for sequence comparisons and phylogenetic analyses

\begin{tabular}{|c|c|c|c|c|c|c|c|}
\hline \multirow[b]{2}{*}{ Species } & \multirow[b]{2}{*}{ Culture accession } & \multirow[b]{2}{*}{ Host/tissue } & \multirow[b]{2}{*}{ Location } & \multicolumn{3}{|c|}{ GenBank accession $^{w}$} & \multirow[b]{2}{*}{ Reference } \\
\hline & & & & ITS & tef1 & $\beta$-tub & \\
\hline $\begin{array}{l}\text { Pseudopestalotiopsis } \\
\text { cocos }\end{array}$ & CBS 272.29 & Cocos nucifera & Indonesia & KM199378 & KM199553 & KM199467 & $\begin{array}{l}\text { Maharachchikumbura } \\
\text { et al. (2014) }\end{array}$ \\
\hline $\begin{array}{l}\text { Pseudopestalotiopsis } \\
\text { indica }\end{array}$ & CBS 459.78 & Hibiscus rosa-sinensis & India & KM199381 & KM199560 & KM199470 & $\begin{array}{l}\text { Maharachchikumbura } \\
\text { et al. (2014) }\end{array}$ \\
\hline $\begin{array}{l}\text { Neopestalotiopsis } \\
\text { rosae }\end{array}$ & CBS 101057 & Rosa sp. & New Zealand & KM199359 & KM199523 & KM199429 & $\begin{array}{l}\text { Maharachchikumbura } \\
\text { et al. (2014) }\end{array}$ \\
\hline $\begin{array}{l}\text { Neopestalotiopsis } \\
\text { rosae }\end{array}$ & CBS 124745 & Paeonia sp. & United States & KM199360 & KM199524 & KM199430 & $\begin{array}{l}\text { Maharachchikumbura } \\
\text { et al. (2014) }\end{array}$ \\
\hline $\begin{array}{l}\text { Neopestalotiopsis } \\
\text { rosae }\end{array}$ & 7927 & Fragaria $\times$ ananassa & Australia & KY271740 & KY271093 & KY271094 & $\mathrm{N} / \mathrm{A}^{\mathrm{x}}$ \\
\hline $\begin{array}{l}\text { Neopestalotiopsis } \\
\text { rosae }\end{array}$ & PEST3 & Fragaria $\times$ ananassa & Egypt & KY688075 & KY688074 & KY688073 & Essa et al. (2018) \\
\hline $\begin{array}{l}\text { Neopestalotiopsis } \\
\text { rosae }\end{array}$ & CRMFRH & Fragaria $\times$ ananassa & Mexico & MN385719 & MN268533 & MN268530 & $\begin{array}{l}\text { Rebollar-Alviter } \\
\text { et al. (2020) }\end{array}$ \\
\hline $\begin{array}{l}\text { Neopestalotiopsis } \\
\text { rosae }\end{array}$ & CRMFRC & Fragaria $\times$ ananassa & Mexico & MN385718 & MN268532 & MN268529 & $\begin{array}{l}\text { Rebollar-Alviter } \\
\text { et al. (2020) }\end{array}$ \\
\hline $\begin{array}{l}\text { Neopestalotiopsis } \\
\text { mesopotamica }\end{array}$ & CBS 299.74 & Eucalyptus sp. & Turkey & KM199361 & KM199541 & KM199435 & $\begin{array}{l}\text { Maharachchikumbura } \\
\text { et al. (2014) }\end{array}$ \\
\hline $\begin{array}{l}\text { Neopestalotiopsis } \\
\text { mesopotamica }\end{array}$ & CBS 137766 & Fragaria $\times$ ananassa & Iran & KM074047 & KM074054 & KM074058 & $\begin{array}{l}\text { Ayoubi and Soleimani } \\
\text { (2016) }\end{array}$ \\
\hline $\begin{array}{l}\text { Neopestalotiopsis } \\
\text { iraniensis }\end{array}$ & CBS 137767 & Fragaria $\times$ ananassa & Iran & KM074045 & KM074053 & KM074056 & $\begin{array}{l}\text { Ayoubi and Soleimani } \\
\text { (2016) }\end{array}$ \\
\hline $\begin{array}{l}\text { Neopestalotiopsis } \\
\text { iraniensis }\end{array}$ & CBS 137768 & Fragaria $\times$ ananassa & Iran & КМ074048 & KM074051 & KM074057 & $\begin{array}{l}\text { Ayoubi and Soleimani } \\
\text { (2016) }\end{array}$ \\
\hline $\begin{array}{l}\text { Neopestalotiopsis } \\
\text { honoluluana }\end{array}$ & CBS 111535 & Telopea sp. & Hawaii (U.S.) & KM199363 & KM199546 & KM199461 & $\begin{array}{l}\text { Maharachchikumbura } \\
\text { et al. (2014) }\end{array}$ \\
\hline $\begin{array}{l}\text { Neopestalotiopsis } \\
\text { foedans }\end{array}$ & CGMCC 3.9123 & Mangrove plant & China & JX398987 & JX399053 & JX399022 & $\begin{array}{l}\text { Maharachchikumbura } \\
\text { et al. (2014) }\end{array}$ \\
\hline $\begin{array}{l}\text { Neopestalotiopsis } \\
\text { clavispora }^{\mathrm{y}}\end{array}$ & TOR-802-803-804 & Fragaria $\times$ ananassa & Spain & KU096879 & KU096881 & KU096880 & Chamorro et al. (2016) \\
\hline $\begin{array}{l}\text { Neopestalotiopsis } \\
\text { clavispora }\end{array}$ & NN043133 & Magnolia sp. & China & JX398979 & JX399045 & JX399014 & $\begin{array}{l}\text { Maharachchikumbura } \\
\text { et al. (2014) }\end{array}$ \\
\hline $\begin{array}{l}\text { Neopestalotiopsis } \\
\text { clavispora }\end{array}$ & NN043011 & Magnolia sp. & China & JX398978 & JX399044 & JX399013 & $\begin{array}{l}\text { Maharachchikumbura } \\
\text { et al. (2014) }\end{array}$ \\
\hline $\begin{array}{l}\text { Neopestalotiopsis } \\
\text { asiatica }\end{array}$ & NN0476380 & Unidentified tree & China & JX398983 & JX399049 & JX399018 & $\begin{array}{l}\text { Maharachchikumbura } \\
\text { et al. (2014) }\end{array}$ \\
\hline $\begin{array}{l}\text { Neopestalotiopsis } \\
\text { javaensis }\end{array}$ & CBS 257.31 & Cocos nucifera & Indonesia & KM199357 & KM199543 & KM199437 & $\begin{array}{l}\text { Maharachchikumbura } \\
\text { et al. (2014) }\end{array}$ \\
\hline $\begin{array}{l}\text { Pestalotiopsis } \\
\text { rhododendri }\end{array}$ & OP086 & Rhododendron sinogrande & China & KC537804 & KC537811 & KC537818 & $\begin{array}{l}\text { Maharachchikumbura } \\
\text { et al. (2014) }\end{array}$ \\
\hline $\begin{array}{l}\text { Pestalotiopsis } \\
\text { trachicarpicola }\end{array}$ & Op068 & Trachycarpus fortunei & China & JQ845947 & JQ845946 & JQ845945 & $\begin{array}{l}\text { Maharachchikumbura } \\
\text { et al. (2014) }\end{array}$ \\
\hline $\begin{array}{l}\text { Neopestalotiopsis } \\
\text { rosae }\end{array}$ & $97-49 \mathrm{~F}$ & Fragaria $\times$ ananassa (fruit) & United States & MK895141 & MK903333 & MK903337 & This studyz \\
\hline $\begin{array}{l}\text { Neopestalotiopsis } \\
\text { rosae }\end{array}$ & 14-691R & Fragaria $\times$ ananassa $($ root $)$ & United States & MK895142 & MK903334 & MK903338 & This studyz \\
\hline $\begin{array}{l}\text { Neopestalotiopsis } \\
\text { rosae }\end{array}$ & $16-337 \mathrm{C}$ & Fragaria $\times$ ananassa $($ crown $)$ & United States & MK895143 & MK903335 & MK903339 & This study ${ }^{z}$ \\
\hline Neopestalotiopsis sp. & $17-43 \mathrm{~L}$ & Fragaria $\times$ ananassa (leaf) & United States & MK895144 & MK903336 & MK903340 & This study ${ }^{z}$ \\
\hline
\end{tabular}

${ }^{w} \beta$-tub, partial beta-tubulin gene; ITS, internal transcribed spacer; tefl, partial translation elongation factor 1-alpha gene.

$x$ N/A, reference not available.

y Isolate from Spain was misidentified as Neopestalotiopsis clavispora.

z Isolates deposited in the GenBank were selected based on morphological, molecular, and pathogenicity studies to represent each strawberry tissue source and Neopestalotiopsis species. Letters R, C, L, and F represent the strawberry tissues from where they were isolated: root, crown, leaf, and fruit, respectively. 
prepared as previously described. Control treatments were sprayed with water. After inoculation, plants were placed inside moist plastic boxes for 3 days and incubated at $24^{\circ} \mathrm{C}\left( \pm 2^{\circ} \mathrm{C}\right)$, with a 12-h photoperiod. Disease incidence (number of symptomatic plants per total number of plants inoculated) and severity (number of lesions per total number of symptomatic leaves per plant) were evaluated 14 days after inoculation. Experiments were conducted twice.

Root and crown inoculation. Pathogenicity of 10 isolates to strawberry transplants was assessed in greenhouse experiments (Table 2). Spore suspensions were produced as previously described. Ten cuttop, bare-root transplants of 'Strawberry Festival' per isolate were inoculated by trimming roots to a uniform length and immersing roots in a suspension of $5 \times 10^{4}$ spores $/ \mathrm{ml}$ or water (control) for $10 \mathrm{~min}$. Plants were potted into 1-liter plastic pots filled with autoclaved soil (Myakka fine sand, Silliceous Hyperthermic Oxyaquic Alorthod) in a greenhouse at $28^{\circ} \mathrm{C}\left( \pm 2^{\circ} \mathrm{C}\right)$ and overhead irrigated during daylight hours for 7 days to increase plant establishment, then irrigated twice daily through drip irrigation for the rest of the experiment. Aboveground symptoms such as stunting, wilting of foliage (drying and death of older leaves while center leaves remained green), or plant death were evaluated weekly. Final disease incidence, expressed as the number of symptomatic plants (stunted, wilted, and dead) per total number of plants inoculated, was evaluated 8 weeks after inoculation. Diseased plants were collected, and isolation from infected tissues onto general isolation medium was performed to confirm Pestalotiopsis-like infections. The experiment was conducted twice.

Data analysis. Mycelial growth and spore production trials were conducted and analyzed in a complete randomized factorial design with two fixed factors (species group and temperature). Mycelial growth data were fitted into a normal distribution, and spore production data were fitted into a Poisson distribution, and an analysis of variance was conducted to determine the significance $(P \leq 0.05)$ of the fixed factors and their interaction. When models were significant, Fisher's least significant difference $(\alpha=0.05)$ test was used for mean separation of the factor species group within the temperature with the highest mycelial growth or spore production. Spore measurement data and disease incidence (proportion) data obtained in the fruit, leaf, and root and crown inoculation trials were fitted into a normal distribution, whereas leaf disease severity was fitted into a Poisson distribution. When models were significant, Fisher's least significant difference $(\alpha=0.05)$ test was used for mean separation of the factor species group for spore measurement data and the factor isolates for disease incidence data. The experiment was considered a random effect, and analyses were performed with the procedure PROC GLIMMIX in SAS version 9.4.

\section{Results}

Molecular characterization. We first conducted phylogenetic analyses by using individual gene regions (data not shown). The divergence between ITS sequences was too low to separate species, and the $\beta$-tub sequences were the most variable to ensure more reliable delimitation of most species. To assess the phylogenetic congruence of the three gene regions, the partition homogeneity test was performed and revealed that these genes were heterogeneous $(P=$ 0.001 ), suggesting different evolutionary histories of the genes and thus a need to use gene-specific substitution models for phylogenetic analysis.

Both maximum likelihood and Bayesian inference analyses revealed similar tree topologies and indicated that all the Florida strawberry isolates should be classified as Neopestalotiopsis sp. (Fig. 2). The phylogenetic tree also revealed a very low genetic diversity among the strawberry isolates from Florida examined in this study based on the ITS, $\beta$-tub, and tefl regions (Fig. 2). The alignments and phylogenetic trees were deposited in TreeBASE (http:// purl.org/phylo/treebase/phylows/study/TB2:S26315).

Twenty-nine strawberry isolates were clustered in the same subclade as Neopestalotiopsis rosae, Neopestalotiopsis javaensis, and Neopestalotiopsis mesopotamica in addition to the Israeli isolate (CBS638.68) (Fig. 2). Our isolates showed 99.45 to $99.78 \%$ identity with the strawberry isolate from Israel originally classified as Pestalotia longisetula (data not shown). The strawberry isolate from

Table 2. Origin and identification of the Neopestalotiopsis spp. isolates used in the morphological characterization and pathogenicity studies ${ }^{\mathrm{u}}$

\begin{tabular}{|c|c|c|c|c|c|}
\hline Isolate $^{v}$ & Species & Strawberry cultivar & Farm, location ${ }^{w}$ & Originating nursery $^{x}$ & Studies $^{\mathbf{y}}$ \\
\hline $97-49 \mathrm{~F}$ & Neopestalotiopsis rosae & 'Earlibrite' & GCREC, Dover & n3 & MG, FA, LA, and RC \\
\hline $11-359 R$ & N. rosae & 'Strawberry Festival' & AF, Plant City & $\mathrm{n} 4$ & $\mathrm{MG}, \mathrm{FA}$, and $\mathrm{RC}$ \\
\hline $11-360 \mathrm{C}$ & N. rosae & 'Winter Dawn' & EM, Dover & $\mathrm{n} 1$ & $\mathrm{MG}, \mathrm{SP}, \mathrm{FA}, \mathrm{LA}$, and RC \\
\hline $13-460 \mathrm{P}$ & N. rosae & - & JM, Wimauma & $\mathrm{n} 1$ & MG, SP, FA, and RC \\
\hline $13-481 R$ & N. rosae & 'Strawberry Festival' & MF, Plant City & $\mathrm{n} 2$ & MG, SP, FA, LA, and RC \\
\hline $14-691 \mathrm{R}$ & N. rosae & 'Florida Radiance' & TJ, Wimauma & $\mathrm{n} 2$ & MG, FA, and RC \\
\hline $16-337 \mathrm{C}$ & N. rosae & 'Florida Radiance' & SF, Plant City & n1 & $\mathrm{MG}, \mathrm{FA}$, and RC \\
\hline $19-381 \mathrm{C}$ & N. rosae & 'Florida Brilliance' & AM, Plant City & $\mathrm{n} 1$ & MG, SP, FA, and LA \\
\hline $17-10 \mathrm{~F}$ & Neopestalotiopsis sp. & 'Florida127’z & RG, Dover & n5 & $\mathrm{MG}, \mathrm{SP}, \mathrm{FA}, \mathrm{LA}$, and RC \\
\hline $17-40 \mathrm{~F}$ & Neopestalotiopsis sp. & 'Florida127' & RG, Dover & n5 & MG, FA, and RC \\
\hline $17-43 \mathrm{~L}$ & Neopestalotiopsis sp. & 'Florida127' & RG, Dover & $\mathrm{n} 5$ & $\mathrm{MG}, \mathrm{SP}, \mathrm{FA}, \mathrm{LA}$, and RC \\
\hline 18-749P & Neopestalotiopsis sp. & - & GF, Wimauma & $\mathrm{n} 1$ & MG, SP, FA, and LA \\
\hline $19-02 \mathrm{~L}$ & Neopestalotiopsis sp. & 'Florida Radiance' & JM, Wimauma & $\mathrm{n} 1$ & MG, SP, FA, and LA \\
\hline $19-44 \mathrm{~F}$ & Neopestalotiopsis sp. & 'Florida127' & RB, Plant City & n5 & MG, SP, FA, and LA \\
\hline $19-48 \mathrm{~F}$ & Neopestalotiopsis sp. & 'Florida Radiance' & SZ, Plant City & $\mathrm{n} 1$ & MG, SP, FA, and LA \\
\hline $19-54 \mathrm{~L}$ & Neopestalotiopsis sp. & 'Florida Radiance' & KD, Plant City & $\mathrm{n} 1$ & MG and SP \\
\hline 19-389L & Neopestalotiopsis sp. & 'Florida Beauty' & CG, Plant City & $\mathrm{n} 1$ & MG and SP \\
\hline $19-459 \mathrm{~L}$ & Neopestalotiopsis sp. & 'Florida127' & FS, Plant City & n5 & MG, SP, FA, and LA \\
\hline $19-461 \mathrm{~L}$ & Neopestalotiopsis sp. & 'Florida Brilliance' & GD, Duette & n6 & MG, SP, FA, and LA \\
\hline $20-05 \mathrm{~L}$ & Neopestalotiopsis sp. & 'Florida Brilliance' & FF, Plant City & $\mathrm{n} 5$ & MG, SP, FA, and LA \\
\hline
\end{tabular}

u -: Information not available.

$\checkmark$ First two digits of isolate codes correspond to the years when they were collected. Letters R, C, P, L, and F represent the strawberry tissues from where they were isolated: root, crown, petiole, leaf, and fruit, respectively.

w Farm: abbreviation codes correspond to strawberry farms in Florida from where isolates were collected. Location: cities in Florida where isolates were collected.

x Originating nursery: the codes represent the nurseries from where the strawberry transplants were obtained. Nurseries n1, n2, and n4 were located in North Carolina, and $\mathrm{n} 3$ and $\mathrm{n} 5$ were located in Massachusetts and California, respectively.

y Morphological characterization and pathogenicity studies performed for strawberry isolates: MG, mycelial growth; SP, spore production; FA, fruit assay; LA, leaf assay; and RC, root/crown inoculation.

z Cultivar 'Florida127' is marketed as Sensation. 
Spain, although previously classified as Neopestalotiopsis clavispora by Chamorro et al. (2016), showed $100 \%$ nucleotide identity to our isolates and other $N$. rosae from strawberry and did not group with the other two $N$. clavispora from magnolia from China (Fig. 2).
The percentage identities to $N$. rosae, $N$. mesopotamica, and $N$. javaensis ranged from 99.67 to $100 \%, 99.45$ to $99.67 \%$, and 99.56 to $99.89 \%$, respectively. We verified a maximum of 3-, 5-, and 4-bp differences in the combined sequences between our isolates and the

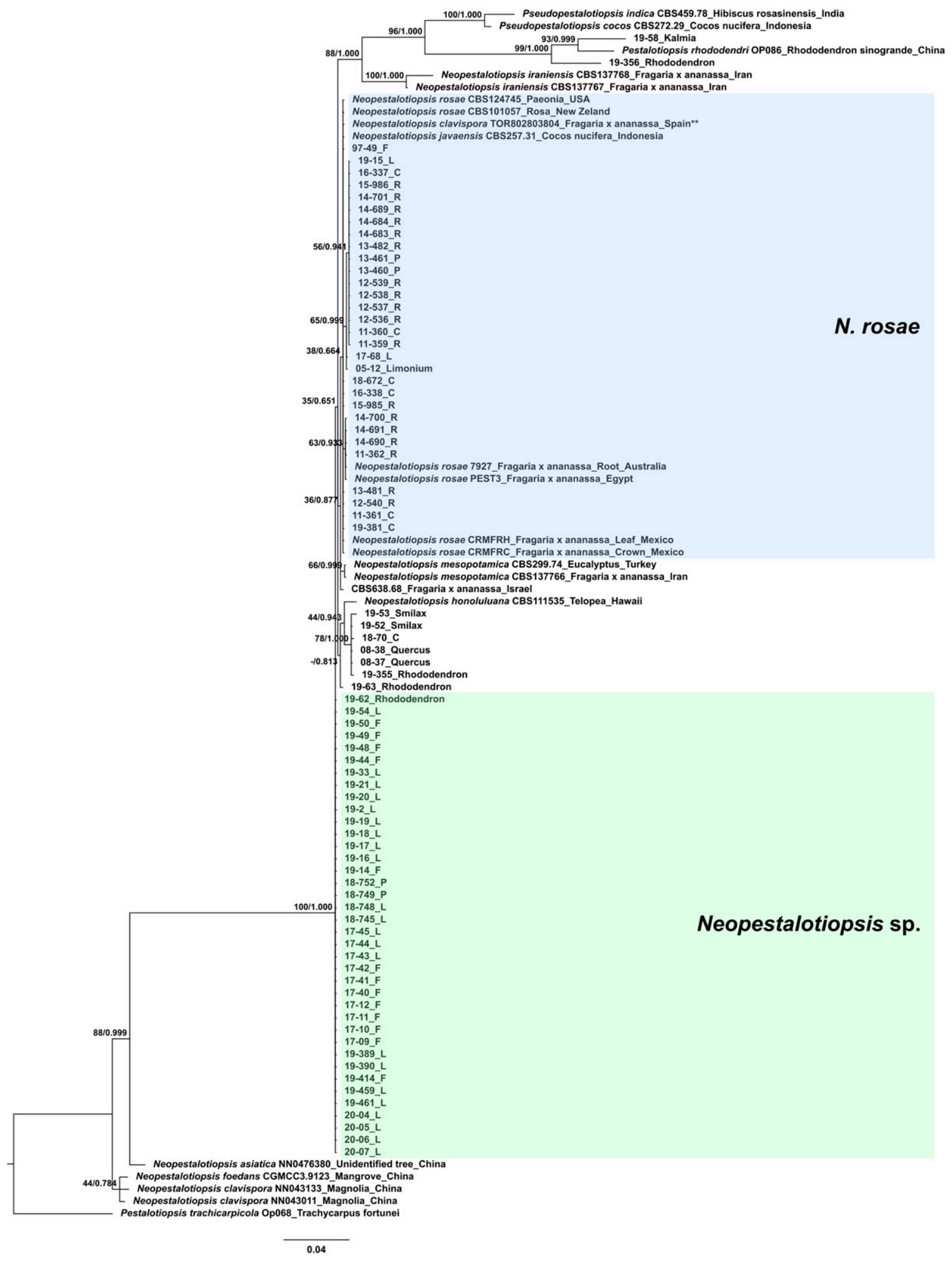

Fig. 2. Phylogenetic consensus tree based on Bayesian inference analyses of the combined alignment of internal transcribed spacer (ITS), elongation factor (tef1), and $\beta$-tubulin $(\beta$-tub) genes of isolates collected in this study and published sequences. Pestalotiopsis trachicarpicola OP068 was used as outgroup taxon. The first two digits of isolate codes correspond to the years they were collected. Letters $\mathrm{R}, \mathrm{C}, \mathrm{P}, \mathrm{L}$, and $\mathrm{F}$ represent the strawberry tissues from where they were isolated: root, crown, petiole, leaf, and fruit, respectively. Names correspond to the alternative hosts from where the isolates originated. Numbers above branches represent maximum likelihood bootstrap support values (before a slash) and Bayesian posterior probabilities (after a slash). Dashes represent missing values because a furcation was not supported by the maximum likelihood method at the given position. Asterisks indicate that the isolate from Spain was misidentified as Neopestalotiopsis clavispora. The scale bar represents the expected number of nucleotide substitutions per site. 
previously mentioned species, respectively. Therefore, these strawberry isolates, mostly collected before 2017 , were identified as $N$. rosae.

The remaining 37 strawberry isolates from our culture collection were clustered together but were not conspecific with any other species in the NCBI database. Most of the isolates obtained during the recent outbreaks in this cluster showed $100 \%$ identity among them and $99.67 \%$ identity to the Israeli strawberry isolate (data not shown). All isolates came from production fields in Florida that acquired transplants from the same nursery sources, including one in North Carolina and one in Ontario, Canada, which received plant stock from the North Carolina nursery. Their sequences were also 100\% similar to an isolate from Rhododendron sp. collected adjacent to the strawberry field at the North Carolina nursery.

Morphological characterization. Colony and spore characterization. Fungal colonies were white, circular with undulate margins, and cottony on the upper surface, regardless of the isolate (Table 3 and Fig. $3 \mathrm{~A}$ to $\mathrm{E})$. However, on the reverse side, the isolates from the recent outbreaks (Neopestalotiopsis sp.) were white to pale yellow (Table 3 and Fig. 3I to J), and N. rosae were pale luteous to orange (Table 3 and Fig. 3F to H). Spores of all isolates were ellipsoid to fusiform, five-celled, and versicolored, with three median colored cells. Basal and apical cells were hyaline, whereas the second cell from the base had a light brown color, the third cell was honey brown, and the fourth cell was brown. Spore length measurements were different between the two groups $(P<0.0001)$ and ranged from 23.0 to $25.8 \mu \mathrm{m}$ (average $=24.5 \mu \mathrm{m}$ ) for the $N$. rosae group and from 24.6 to $28.7 \mu \mathrm{m}$ (average $=26.9 \mu \mathrm{m}$ ) for the new Neopestalotiopsis sp. group (Table 3). There was no significant difference between the species groups $(P>0.05)$ for spore width and basal and apical length measurements. Spore width measurements ranged from 6.8 to $8.5 \mu \mathrm{m}$ (average $=7.4 \mu \mathrm{m}$ ) for the $N$. rosae group and from 6.3 to $8.8 \mu \mathrm{m}$ (average $=7.4 \mu \mathrm{m}$ ) for the new Neopestalotiopsis sp. group (Table 3). Spores had one basal and two to four apical appendages (mostly three), with average lengths ranging from 5.1 to $12.3 \mu \mathrm{m}$ (average $=8.5 \mu \mathrm{m})$ and 20.3 to $36.3 \mu \mathrm{m}$ (average $=29.2 \mu \mathrm{m})$, respectively, for the $N$. rosae group and from 7.3 to $9.5 \mu \mathrm{m}$ (average
$=8.3 \mu \mathrm{m}$ ) and 19.3 to $33.1 \mu \mathrm{m}$ (average $=29.0 \mu \mathrm{m}$ ), respectively, for the new Neopestalotiopsis sp. group (Table 3).

Mycelial growth and spore production at different temperatures. Overall, differences between species groups, temperatures, and the interaction species group $\times$ temperature were observed for mycelial growth and spore production. Mycelial growth was inhibited at 5 and $35^{\circ} \mathrm{C}$ for all the isolates tested, and spores were not produced at $10^{\circ} \mathrm{C}$. The highest mycelial growth was observed at $25^{\circ} \mathrm{C}$ in both assays. The optimum temperatures for spore production were between 25 and $30^{\circ} \mathrm{C}$. Mycelial growth (Fig. 4A) and spore production (Fig. 4B) were usually higher for the Neopestalotiopsis sp. isolates from the recent outbreaks than for $N$. rosae $(P<0.05)$.

Pathogenicity tests. Fruit inoculation. In pathogenicity tests, not all isolates were able to produce Pestalotiopsis-like symptoms on inoculated fruit (Table 4). In the first and second assays, disease incidence on inoculated fruit varied from 0 to $100 \%$ and from 13.9 to $88.9 \%$, respectively (Table 4). Fruit inoculated with the Neopestalotiopsis sp. isolates from the recent outbreaks showed disease incidences ranging from 88.9 to $100 \%$ for the first assay and 41.7 to $88.9 \%$ for the second assay, which were usually higher than in fruit inoculated with $N$. rosae isolates (Table 4). Fruit inoculated with $N$. rosae isolates $97-49 \mathrm{~F}, 11-359 \mathrm{R}$, and 13-460P did not develop symptoms, whereas disease incidence were $\leq 25 \%$ for the other isolates, regardless of the assay. Spores from symptomatic fruit were morphologically identical to the original colonies used for inoculum production. Noninoculated fruit did not show any disease symptoms.

Leaf inoculation. All tested isolates were able to produce Pestalotiopsis-like lesions on strawberry leaves (Table 4). However, Neopestalotiopsis sp. isolates from the recent outbreaks were more aggressive than $N$. rosae isolates (Table 4). Plant disease incidence varied from 25 to $41.7 \%$ in plants inoculated with $N$. rosae and from 58.3 to $100 \%$ in strawberries inoculated with Neopestalotiopsis sp. isolates from the recent outbreaks (Table 4). The number of lesions per symptomatic leaf per plant was greater in plants inoculated with the Neopestalotiopsis sp. isolates from the recent outbreaks $(P=$ 0.011 ), ranging from 0.63 to 1.44 lesions/diseased leaves/plant,

Table 3. Morphological characteristics of the Neopestalotiopsis spp. isolates from Florida strawberry

\begin{tabular}{|c|c|c|c|c|c|c|c|}
\hline \multirow[b]{2}{*}{ Isolate $^{\mathrm{y}}$} & \multirow[b]{2}{*}{ Species } & \multicolumn{2}{|c|}{$\begin{array}{c}\text { Conidium size }(\mu \mathrm{m}), \\
\text { mean }(\mathrm{SD})\end{array}$} & \multirow{2}{*}{$\begin{array}{c}\text { Basal appendage } \\
\text { length }(\mu \mathrm{m}), \text { mean }(\mathrm{SD})\end{array}$} & \multirow{2}{*}{$\begin{array}{c}\text { Apical appendage } \\
\text { length }(\mu \mathrm{m}), \text { mean }(\mathrm{SD})\end{array}$} & \multicolumn{2}{|r|}{ Colony color } \\
\hline & & Length & Width & & & Upper & Bottom \\
\hline $97-49 \mathrm{~F}$ & Neopestalotiopsis rosae & $23.0(0.44)$ & $7.0(0.10)$ & $6.7(0.37)$ & $29.8(0.83)$ & Whitish & Pale luteous to orange \\
\hline $11-359 R$ & N. rosae & $24.1(0.46)$ & $8.5(0.22)$ & $9.0(0.52)$ & $29.7(0.39)$ & Whitish & Pale luteous to orange \\
\hline $11-360 \mathrm{C}$ & N. rosae & $23.1(0.51)$ & $6.8(0.14)$ & $7.7(0.29)$ & $20.3(0.48)$ & Whitish & Pale luteous to orange \\
\hline $13-460 \mathrm{P}$ & N. rosae & $24.5(0.42)$ & $8.0(0.23)$ & $8.7(0.44)$ & $30.0(0.72)$ & Whitish & Pale luteous to orange \\
\hline $13-481 R$ & N. rosae & $25.5(0.29)$ & $6.8(0.19)$ & $5.1(0.21)$ & $25.1(0.48)$ & Whitish & Pale luteous to orange \\
\hline $14-691 \mathrm{R}$ & N. rosae & $25.0(0.37)$ & $7.0(0.11)$ & $9.7(0.63)$ & $32.1(0.54)$ & Whitish & Pale luteous to orange \\
\hline $16-337 \mathrm{C}$ & N. rosae & $24.9(0.43)$ & $8.2(0.2)$ & $8.4(0.65)$ & $30.6(0.72)$ & Whitish & Pale luteous to orange \\
\hline $19-381 C$ & N. rosae & $25.8(0.42)$ & $7.0(0.09)$ & $12.3(0.75)$ & $36.3(0.70)$ & Whitish & Pale luteous to orange \\
\hline Average & & $24.5(0.37)$ & $7.4(0.25)$ & $8.5(0.75)$ & $29.2(1.68)$ & & \\
\hline $17-10 \mathrm{~F}$ & Neopestalotiopsis sp. & $24.6(0.36)$ & $7.1(0.09)$ & $7.7(0.60)$ & $26.1(0.59)$ & Whitish & Whitish to pale yellow \\
\hline $17-40 \mathrm{~F}$ & Neopestalotiopsis sp. & $27.4(0.31)$ & $7.4(0.10)$ & $7.21(0.31)$ & $30.6(0.63)$ & Whitish & Whitish to pale yellow \\
\hline $17-43 \mathrm{~L}$ & Neopestalotiopsis sp. & $26.0(0.43)$ & $7.2(0.15)$ & $8.4(0.44)$ & $30.8(0.74)$ & Whitish & Whitish to pale yellow \\
\hline $18-749 \mathrm{P}$ & Neopestalotiopsis sp. & $28.2(0.43)$ & $6.3(0.13)$ & $7.7(0.33)$ & $26.4(0.47)$ & Whitish & Whitish to pale yellow \\
\hline $19-02 \mathrm{~L}$ & Neopestalotiopsis sp. & $27.3(0.5)$ & $7.1(0.16)$ & $7.6(0.40)$ & $30.7(0.55)$ & Whitish & Whitish to pale yellow \\
\hline $19-44 \mathrm{~F}$ & Neopestalotiopsis sp. & $27.2(0.62)$ & $7.7(0.16)$ & $8.9(0.54)$ & $27.0(0.54)$ & Whitish & Whitish to pale yellow \\
\hline $19-48 \mathrm{~F}$ & Neopestalotiopsis sp. & $26.2(0.41)$ & $6.8(0.12)$ & $7.3(0.31)$ & $28.5(0.76)$ & Whitish & Whitish to pale yellow \\
\hline $19-54 \mathrm{~L}$ & Neopestalotiopsis sp. & $27.2(0.37)$ & $7.6(0.18)$ & $9.5(0.41)$ & $32.4(0.51)$ & Whitish & Whitish to pale yellow \\
\hline 19-389L & Neopestalotiopsis sp. & $28.7(0.43)$ & $7.9(0.13)$ & $8.9(0.43)$ & $33.1(0.60)$ & Whitish & Whitish to pale yellow \\
\hline $19-459 \mathrm{~L}$ & Neopestalotiopsis sp. & $26.5(0.45)$ & $8.8(0.25)$ & $9.8(0.78)$ & $30.6(0.77)$ & Whitish & Whitish to pale yellow \\
\hline $19-461 \mathrm{~L}$ & Neopestalotiopsis sp. & $28.7(0.56)$ & $8.0(0.19)$ & $9.0(0.44)$ & $32.0(0.45)$ & Whitish & Whitish to pale yellow \\
\hline $20-05 \mathrm{~L}$ & Neopestalotiopsis sp. & $24.6(0.63)$ & $6.8(0.14)$ & $8.1(0.42)$ & $19.3(0.52)$ & Whitish & Whitish to pale yellow \\
\hline Average & & $26.9(0.40)$ & $7.4(0.19)$ & $8.34(0.25)$ & $29.0(1.11)$ & & \\
\hline $\operatorname{Pr}>F^{\mathrm{z}}$ & & $<0.0001$ & 0.7649 & 0.6868 & 0.3629 & & \\
\hline
\end{tabular}

${ }^{y}$ First two digits of isolate codes correspond to the years when they were collected. Letters R, C, P, L, and F represent the strawberry tissues from where they were isolated: root, crown, petiole, leaf, and fruit, respectively.

${ }^{\text {z }}$ Probability of a greater $F$ value associated with type III test of fixed effect for each species group. 
compared with 0.25 to 0.92 lesions/diseased leaves/plant for $N$. rosae (Table 4). Noninoculated plants did not show any typical disease symptoms.

Root and crown inoculation. All isolates were able to infect and produce root and crown rot symptoms. Early aboveground symptoms such as wilting were observed as soon as 12 days after root inoculation, and plant stunting and death were observed starting 3 weeks after inoculation. Final disease incidence recorded 8 weeks after inoculation ranged from 35 to $90 \%$ and was not significantly different between the isolates (data not shown). Morphological characteristics of isolates obtained by culturing of necrotic crown and root tissue and spores produced were identical to those in the original inoculum. Pestalotiopsis-like fungi were not recovered from any of the noninoculated plants.

\section{Discussion}

In this study, we identified Neopestalotiopsis as the genus affecting strawberry production fields in Florida. Morphological characteristics and pathogenicity assays together with phylogenetic analyses and an appraisal of the literature demonstrated that although there was low genetic diversity among the strawberry isolates, there was a clear separation of the isolates in two groups. The first group included isolates recovered over a period of several years, which were identified as $N$. rosae. Although it could be found on leaves and fruit, $N$. rosae was most commonly found causing symptoms on roots and crowns, contributing to plant establishment difficulties. Most isolates recovered during the recent outbreaks were genetically distinct and may belong to a new Neopestalotiopsis sp., and they were isolated mainly from leaves and fruit.

The taxonomy of these fungi is poorly understood and has gone through multiple reclassifications based on morphological characteristics in the past and phylogenetic analyses more recently. The first reports of the pathogen (Pestalotia longisetula) in strawberry (Howard and Albregts 1973; Kenneth et al. 1968) followed the description of Guba (1961), who characterized the fungus morphology for isolates from canes of Rosa sp., which, like strawberry plants, belongs to the Rosaceae. Based on morphological characteristics, $P$. longisetula was subsequently reclassified as Pestalotiopsis longisetula (Steyaert 1949, 1955). More recently, strawberry isolates were identified as belonging to the genus Neopestalotiopsis, in reports describing a pathogen of strawberry roots and crowns (Chamorro et al. 2016; Essa et al. 2018; Mahapatra et al. 2018; Obregón et al. 2018).
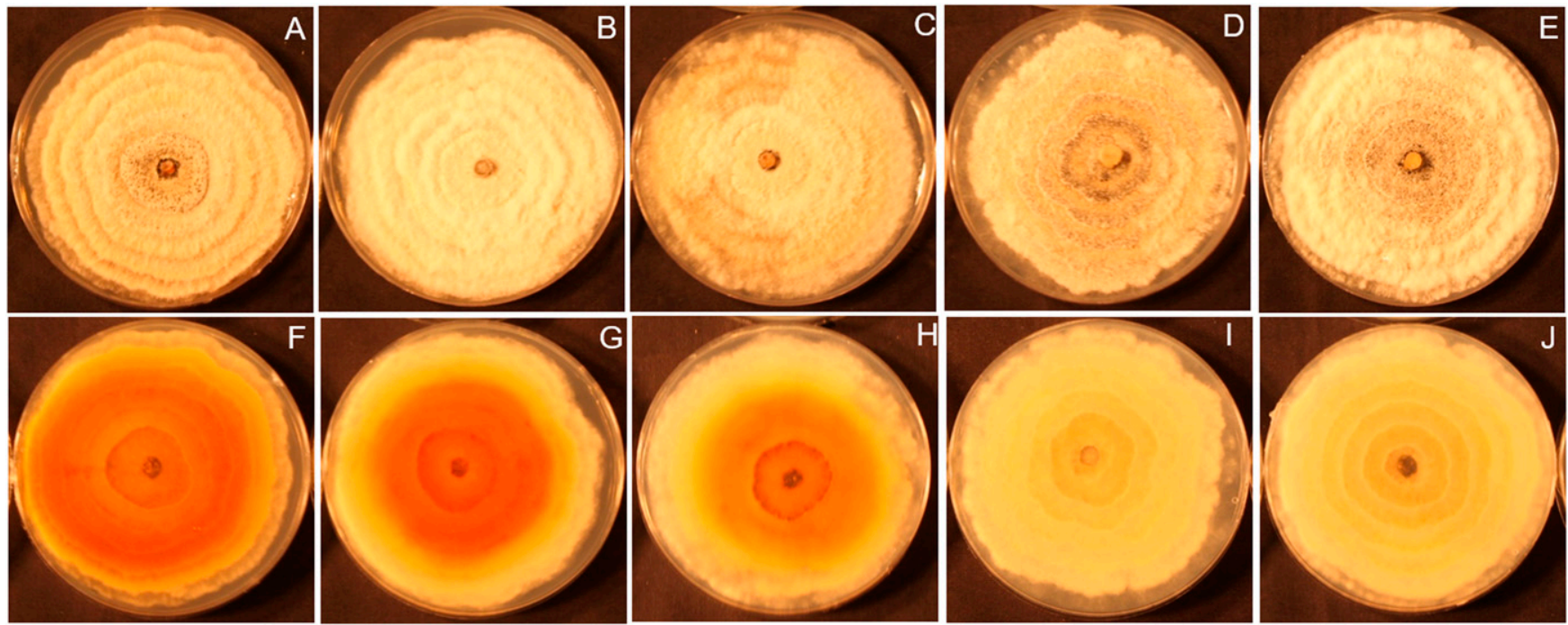

Fig. 3. Neopestalotiopsis spp. A to E, Upper side and F to J, bottom side morphology of isolates from strawberry roots $(\mathbf{A}, \mathbf{F})$, crowns $(\mathbf{B}, \mathbf{G})$, petioles $(\mathbf{C}, \mathbf{H})$, leaves $(\mathbf{D}, \mathbf{I})$, and fruit $(\mathbf{E}, \mathrm{J})$ from Neopestalotiopsis rosae $(\mathbf{A}$ to $\mathbf{C}, \mathbf{F}$ to $\mathbf{H})$ and Neopestalotiopsis sp. isolates from the recent outbreaks $(\mathbf{D}, \mathbf{E}, \mathrm{I}, \mathrm{J})$ growing on potato dextrose agar for 7 days.
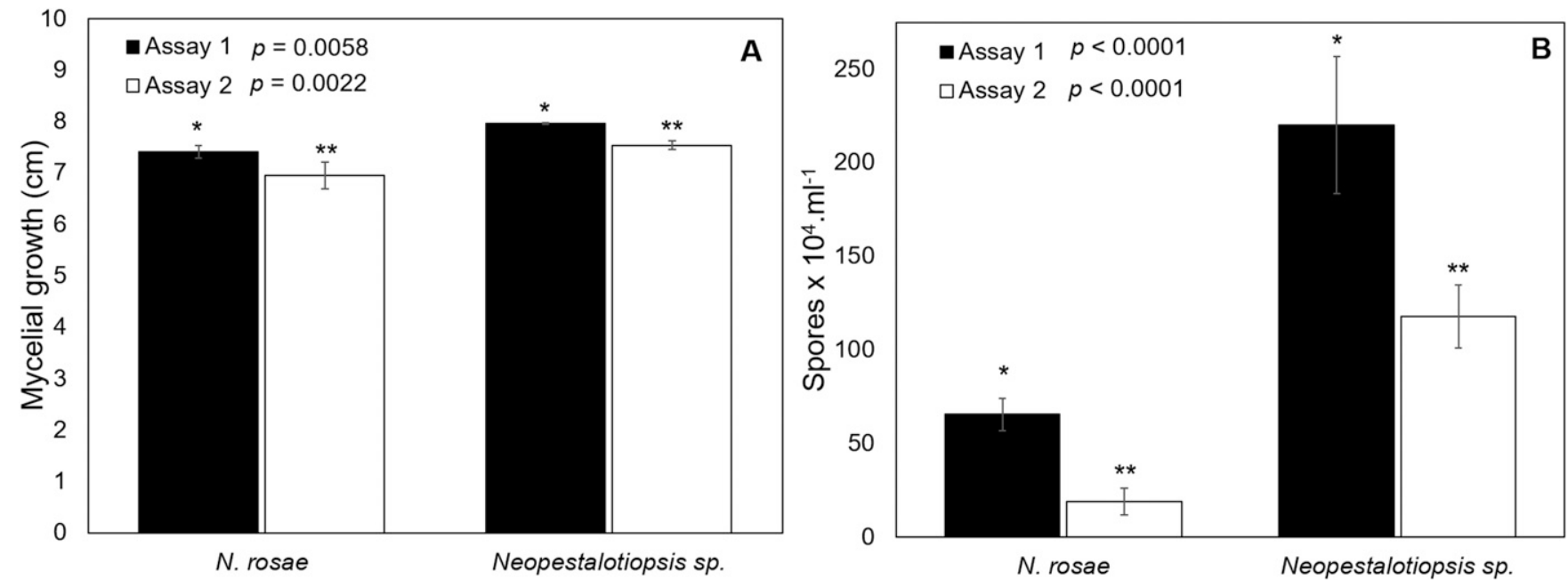

Fig. 4. A, Mycelial growth $(\mathrm{cm})$ at $25^{\circ} \mathrm{C}$ and B, spore production $\left(\times 10^{4} / \mathrm{ml}\right)$ at 30 and $25^{\circ} \mathrm{C}$ for assays 1 and 2 , respectively, of Neopestalotiopsis rosae and Neopestalotiopsis sp. strawberry isolates. Assays 1 and 2, with two experiments each, were performed in June 2018 and March 2020, respectively. Data are the means of two experiments for each assay. Ranges within bars represent mean standard error. Single and double asterisks indicate significant differences for assays 1 and 2, respectively. 
Most of the recent taxonomy of Pestalotiopsis-like organisms is based on the reclassification suggested by Maharachchikumbura et al. (2014). However, some species were classified and named after only a couple of representative isolates. Moreover, overall branch-length support values in the Neopestalotiopsis genus were low, as also observed in our phylogenetic studies. Therefore, the current data might be insufficient to determine species boundaries within the Neopestalotiopsis genus, and additional gene loci might be needed for better species separations.

Most Florida strawberry isolates collected before 2017 and a strawberry isolate from Israel collected in the 1960s (CBS 638.38) were clustered in the same subclades as $N$. rosae, $N$. javaensis, and $N$. mesopotamica. However, branch-length support values for species separation were low, as was observed by Maharachchikumbura et al. (2014). For instance, the percentage identities of $N$. rosae to $N$. mesopotamica and $N$. javaensis were 99.67 and $99.89 \%$, respectively. Moreover, Maharachchikumbura et al. (2014) reported a 2-bp difference in the ITS sequence between $N$. javaensis and $N$. rosae in addition to longer and thinner spores and shorter apical appendages in the former. Additionally, $N$. rosae is differentiated from $N$. mesopotamica by its wider spores and shorter apical appendages (Maharachchikumbura et al. 2014). Following morphological characteristics of the three species, our isolates fitted the description of $N$. rosae, with similar spore color, shape, and dimensions (Maharachchikumbura et al. 2014), as well as high genetic identity (99.67 to 100\%). Moreover, four $N$. rosae isolates used in the phylogenetic analysis were isolated from strawberry tissues, mainly roots and crowns, in Australia, Mexico, and Egypt (Essa et al. 2018; Rebollar-Alviter et al. 2020) (Table 1). Furthermore, one $N$. rosae isolate originated from a stem lesion in Rosa sp. (Maharachchikumbura et al. 2014). Similarly, P. longisetula was isolated from Rosa sp. canes by Guba (1961), suggesting that $N$. rosae might be a synonym of $P$. longisetula.

Most Florida strawberry isolates collected from petioles, leaves, and fruit during the recent outbreaks were not clustered with any other species reported by Maharachchikumbura et al. (2014) or from the NCBI database. Although spore morphology was similar to that of the other Florida strawberry isolates identified as $N$. rosae, spores were longer, and colony color was different (Table 3 and Fig. 3I and J). Moreover, mycelial growth and spore production were higher in in vitro assays (Fig. 4), and symptoms on fruit and leaves of strawberry were more severe (Table 4), suggesting they might be more aggressive and confirming observations from the recent outbreaks in commercial strawberry fields in Florida.

Interestingly, a similar outbreak was also observed in Mexico during the 2018-2019 strawberry season, where similar symptoms on leaves, petioles, and crowns were reported, and diseased plants showed reduced growth and died approximately 1 month after transplanting (Rebollar-Alviter et al. 2020). However, these isolates were identified as $N$. rosae and were genetically different than the isolates from the recent outbreaks in Florida. This was also true for one of our leaf isolates collected in 2017 (Fig. 2); however, the isolate was from transplants originating from a different nursery source than all other isolates associated with the recent outbreak. In the case of the report from Mexico, there is no reference about the nursery source for the transplants.

Although a recent report from Spain classified strawberry isolates as $N$. clavispora (Chamorro et al. 2016), and reports from India and Argentina followed this description (Mahapatra et al. 2018; Obregón et al. 2018), none of these studies performed a complete phylogenetic analysis by using the combination of multiple genes to fully characterize strawberry isolates, as done in our study and the ones by Ayoubi and Soleimanil (2016), Essa et al. (2018) and RebollarAlviter et al. (2020). Previous authors based their classification on similarities of individual genes, which might have led to misclassifications. For example, the strawberry isolate reported as $N$. clavispora by Chamorro et al. (2016) showed $100 \%$ nucleotide identity with $N$. rosae for the combined analyzed regions in our study. In addition, the isolate was similar to our isolates from before the disease outbreaks and did not phylogenetically group with other $N$. clavispora.

Before 2002, the pathogen was known for infecting strawberry fruit exclusively. Recently, reports worldwide have shown it also

Table 4. Disease incidence on strawberry fruit and leaves of Sensation 'Florida127' plants inoculated with Neopestalotiopsis spp. isolates ${ }^{\mathrm{u}}$

\begin{tabular}{|c|c|c|c|c|c|}
\hline \multirow[b]{2}{*}{ Isolate $^{\mathrm{v}}$} & \multirow[b]{2}{*}{ Species } & \multicolumn{2}{|c|}{ Fruit $^{w}$} & \multicolumn{2}{|r|}{ Leaf ${ }^{x}$} \\
\hline & & Incidence (\%) assay $\mathbf{1}^{\mathrm{y}}$ & Incidence $(\%)$ assay $2^{y}$ & Incidence $(\%)^{\mathbf{y}}$ & Severity (lesions/symptomatic leaves) \\
\hline $97-49 \mathrm{~F}$ & Neopestalotiopsis rosae & $0.0 \mathrm{c}$ & - & $25.0 \mathrm{e}$ & $0.25 \mathrm{e}$ \\
\hline $11-359 R$ & N. rosae & $0.0 \mathrm{c}$ & - & - & - \\
\hline $11-360 \mathrm{C}$ & N. rosae & $5.5 \mathrm{c}$ & $25.0 \mathrm{de}$ & $33.3 \mathrm{de}$ & $0.33 \mathrm{e}$ \\
\hline $13-460 \mathrm{P}$ & N. rosae & $0.0 \mathrm{c}$ & - & - & - \\
\hline $13-481 R$ & N. rosae & $25.0 \mathrm{~b}$ & $13.9 \mathrm{e}$ & $25.0 \mathrm{e}$ & $0.42 \mathrm{de}$ \\
\hline $16-337 \mathrm{C}$ & N. rosae & $25.0 \mathrm{~b}$ & - & - & - \\
\hline $19-381 \mathrm{C}$ & N. rosae & - & $13.9 \mathrm{e}$ & 41.7 cde & 0.92 abcde \\
\hline $17-10 \mathrm{~F}$ & Neopestalotiopsis sp. & $97.2 \mathrm{a}$ & $73.3 \mathrm{ab}$ & $75.0 \mathrm{abc}$ & $1.08 \mathrm{abcd}$ \\
\hline $17-40 \mathrm{~F}$ & Neopestalotiopsis sp. & $100.0 \mathrm{a}$ & - & - & - \\
\hline $17-43 \mathrm{~L}$ & Neopestalotiopsis sp. & $88.9 \mathrm{a}$ & - & $100.0 \mathrm{a}$ & $1.44 \mathrm{abc}$ \\
\hline $18-749 \mathrm{P}$ & Neopestalotiopsis sp. & - & $60.0 \mathrm{bc}$ & $83.3 \mathrm{ab}$ & $1.44 \mathrm{abc}$ \\
\hline $19-02 \mathrm{~L}$ & Neopestalotiopsis sp. & - & $58.3 \mathrm{bc}$ & $100.0 \mathrm{a}$ & $1.76 \mathrm{a}$ \\
\hline $19-44 \mathrm{~F}$ & Neopestalotiopsis sp. & - & $47.8 \mathrm{~cd}$ & 58.3 bcde & 0.78 bcde \\
\hline $19-48 \mathrm{~F}$ & Neopestalotiopsis sp. & - & $41.7 \mathrm{~cd}$ & $75.0 \mathrm{abc}$ & $1.44 \mathrm{abc}$ \\
\hline $19-459 \mathrm{~L}$ & Neopestalotiopsis sp. & - & $88.9 \mathrm{a}$ & 58.3 bcde & $0.63 \mathrm{cde}$ \\
\hline $19-461 \mathrm{~L}$ & Neopestalotiopsis sp. & - & $44.4 \mathrm{~cd}$ & $75.0 \mathrm{abc}$ & $1.52 \mathrm{ab}$ \\
\hline $20-05 \mathrm{~L}$ & Neopestalotiopsis sp. & - & $52.8 \mathrm{bc}$ & $66.7 \mathrm{abcd}$ & 0.78 bcde \\
\hline $\operatorname{Pr}>F^{\mathrm{z}}$ & & $<0.0001$ & $<0.0001$ & 0.008 & 0.0041 \\
\hline
\end{tabular}

u - : Data not available.

$v$ The first two digits of isolate codes correspond to the years they were collected. R, C, P, L, and F represent the strawberry tissues from which they were isolated: root, crown, petiole, leaf, and fruit, respectively.

${ }^{w}$ Nonwounded fruit harvested before commercial maturity (white-pink stage) were inoculated with a $40-\mu \mathrm{l}$ aliquot of conidial suspension (104 spores $\left./ \mathrm{ml}\right)$ and incubated at $24^{\circ} \mathrm{C}\left( \pm 2^{\circ} \mathrm{C}\right)$ in sealed humid chambers in two fruit assays, with two experiments each. Assay 1 was performed in March 2017, and assay 2 was conducted in March 2020. Incidence was assessed 7 days after inoculation.

x Strawberry plant leaves were inoculated with an atomizer by spraying 25 to $50 \mathrm{ml}$ of spore suspensions of each isolate $\left(10^{4}\right.$ spores $\left./ \mathrm{ml}\right)$ and incubated at $24^{\circ} \mathrm{C}$ $\left( \pm 2^{\circ} \mathrm{C}\right.$ ), with a 12 -h photoperiod. Disease incidence (number of symptomatic plants per total number of plants inoculated) and severity (number of lesions per total number of symptomatic leaves per plant) were evaluated 14 days after inoculation.

y Data are the means of two experiments for each assay. Values in columns followed by the same letters are not significantly different according to Fisher's protected least significant difference test $(\alpha=0.05)$.

z Probability of a greater $F$ value associated with type III test of fixed effect for each isolate. 
infects other parts of the strawberry plants (Ayoubi and Soleimani 2016; Camili et al. 2002; Chamorro et al. 2016; Van Hemelrijck et al. 2017). During the 2012-2013 Florida strawberry season, the pathogen was repeatedly isolated from roots and crowns of weak, stunted, and dying transplants (Supplementary Fig. S1; Mertely et al. 2015). However, it was not uncommon to observe concomitant infections by other crown and root rot strawberry pathogens. Thus, during the stressful establishment period after transplanting, weakened plants may be more susceptible to root and crown infections, and $N$. rosae might act as an opportunistic pathogen.

Conversely, the most recent Neopestalotiopsis sp. isolates, commonly isolated from symptomatic leaves and fruit, were responsible for the serious outbreaks in Florida (Fig. 1) and caused significant crop losses in commercial fields, suggesting higher aggressiveness. Moreover, the recent outbreaks occurred in commercial fields whose transplants originated from the same nursery sources, including one in North Carolina and one in Ontario, Canada, which received plant stock from the North Carolina nursery. Furthermore, all isolates originating from this nursery were $100 \%$ identical. These observations suggest that the pathogen might be transported with strawberry transplants from specific nurseries, as has been reported for other strawberry pathogens (Forcelini and Peres 2018; Howard et al. 1992; Oliveira et al. 2017; Pettitt and Pegg 1994).

Interestingly, the strawberry isolates from the recent outbreak were very similar to an isolate (19-62) obtained from native Rhododendron plants (Fig. 2) growing next to the strawberry transplant production field from where the plants originated (Supplementary Fig. S2). The sexual state of Pestalotiopsis, known as Pestalosphaeria, is commonly found on leaves of Rhododendron maximum growing in North Carolina and was first reported in Macon County (Barr 1975), the same county where the strawberry nursery is located. Considering that some of the $N$. rosae isolates originated from transplants from this same nursery and that other isolates collected from native Rhododendron plants clustered with different Neopestalotiopsis and Pestalotiopsis species (Fig. 2), we could hypothesize that the pathogen was always present in the area and that genetic recombination might be happening. This question and the pathogen dissemination between hosts need to be explored further. Dissemination from the native Rhododendron to strawberry transplants may have been facilitated by Hurricane Florence in the fall of 2018, which was responsible for heavy rains and strong winds throughout North Carolina. However, host specificity and epidemiological studies are needed to confirm these observations and elucidate the disease cycle.

A trifecta of events may have contributed to the recent outbreaks. Two were the introduction of the pathogen with nursery transplants and reported failure of most fungicides registered for strawberry (Whitaker et al. 2019). The third was the occurrence of favorable environmental conditions at the end of December, characterized by unusually prolonged rains followed by days of warm weather (20 to $24^{\circ} \mathrm{C}$ ). These conditions conform to the pathogen temperature requirements. In fact, our in vitro studies have demonstrated that temperatures between 25 and $30^{\circ} \mathrm{C}$ are optimal for pathogen growth and sporulation. Moreover, preliminary studies have shown that inoculation of different strawberry cultivars with isolates originated from leaves were able to show different levels of susceptibility between cultivars, but none were considered resistant (Mertely et al. 2019).

In this study, we add to the taxonomic knowledge of Neopestalotiopsis spp. affecting strawberry. Isolates identified as N. rosae are associated mostly with root and crown rots in weakened plants, being responsible for plant establishment difficulties. The new Neopestalotiopsis sp. isolates, commonly associated with leaf and fruit symptoms, seem to be more aggressive, confirming observations from the recent severe outbreaks and crop losses in commercial strawberry fields in Florida. Additional research is needed to elucidate the origin of the new pathogen and the disease cycle and to develop integrated strategies for disease management in strawberry nursery and production fields.

\section{Acknowledgments}

We thank Bruno Rossito De Marchi, Marcus V. Marin, and Ronel Josue Argueta Menendez for their assistance.

\section{Literature Cited}

Ara, T., Monzur, S., Saand, M. A., Islam, R., Alam, S., and Hossain, M. 2017. The first report of Pestalotiopsis sp. causing crown rot disease on strawberry (Fragaria X ananassa Duch.) in Bangladesh and evaluation of fungicide activity. Int. J. Biosci. 11:350-358.

Ayoubi, N., and Soleimani, M. 2016. Strawberry fruit rot caused by Neopestalotiopsis iranensis sp. nov., and N. mesopotamica. Curr. Microbiol. 72:329-336.

Barr, M. E. 1975. Pestalosphaeria, a new genus in the Amphisphaeriaceae Mycologia 67:187-194.

Bazinet, A. L., Zwickl, D. J., and Cummings, M. P. 2014. A gateway for phylogenetic analysis powered by grid computing featuring GARLI 2.0. Syst. Biol. 63:812-818.

Brown, M. 2003. Florida strawberry production and marketing. Pages 31-42 in: The Strawberry: A Book for Growers. N. F. Childers, ed. Dr. Norman N. Childers Publications, Gainesville, FL.

Camili, E. C., Carbonari, M., and Souza, N. L. 2002. Caracterização de Pestalotiopsis longisetula e sua patogenicidade em morango. Summa Phytopathol. 28:213-214.

Chamorro, M. C., Aguado, A., and De los Santos, B. 2016. First report of root and crown rot caused by Pestalotiopsis clavispora (Neopestalotiopsis clavispora) on strawberry in Spain. Plant Dis. 100:1495.

Embaby, E. M. 2007. Pestalotia fruit rot on strawberry plants in Egypt. Egypt. J. Phytopathol. 35:99-110.

Essa, T. A., Kamel, S. M., Ismail, A. M., and El-Ganainy, S. M. 2018 Characterization and chemical control of Neopestalotiopsis rosae the causal agent of strawberry root and crown rot in Egypt. Egypt. J. Phytopathol. 46:1-19.

FAOSTAT. 2020. Available at: http://www.fao.org/faostat/en/\#data/QC

Farris, J. S., Källersjö, M., Kluge, A. G., and Bult, C. 1994. Testing significance of incongruence. Cladistics 10:315-319.

Forcelini, B. B., and Peres, N. A. 2018. Widespread resistance to QoI fungicides of Colletotrichum acutatum from strawberry nurseries and production fields. Plant Health Prog. 19:338-341.

Glass, N. L., and Donaldson, G. C. 1995. Development of primer sets designed for use with the PCR to amplify conserved genes from filamentous ascomycetes. Appl. Environ. Microbiol. 61:1323-1330.

Guba, E. F. 1961. Monograph of Pestalotia and Monochaetia. Harvard University Press, Cambridge, MA.

Howard, C. M., and Albregts, E. E. 1973. A strawberry fruit rot caused by Pestalotia longisetula. Phytopathology 63:862-863.

Howard, C. M., Maas, J. L., Chandler, C. K., and Albregts, E. E. 1992. Anthracnose of strawberry caused by the Colletotrichum complex in Florida. Plant Dis. 76:976-981.

Jeewon, R., Liew, E. C. Y., Simpson, J. A., Hodgkiss, J., and Hyde, K. D. 2003. Phylogenetic significance of morphological characters in the taxonomy of Pestalotiopsis species. Mol. Phylogenet. Evol. 27:372-383.

Katoh, K., Misawa, K., and Miyata, T. 2002. MAFFT: a novel method for rapid multiple sequence alignment based on fast Fourier transform. Nucleic Acids Res. 30:3059-3066.

Katoh, K., and Standley, D. M. 2013. MAFFT multiple sequence alignment software version 7: improvements in performance and usability. Mol. Biol. Evol. 30:772-780.

Kenneth, R. G., Barkai-Golan, R., and Netzer, D. 1968. A Pestalotia fruit rot of strawberry in Israel. Plant Dis. Rep. 52:472-474.

Liu, F., Bonthond, G., Groenewald, J. Z., Cai, L., and Crous, P. W. 2019. Sporocadaceae, a family of coelomycetous fungi with appendage-bearing conidia. Stud. Mycol. 92:287-415

Maas, J. L. 1998. Compendium of Strawberry Diseases, 2nd ed. American Phytopathological Society Press, Saint Paul, MN.

Mahapatra, S., Banerjee, J., Kumar, K., Pramanik, S., Pramanik, K., Islam, S., and Das, S. 2018. Leaf spot and fruit rot of strawberry caused by Neopestalotiopsis clavispora in Indo-Gangetic plains of India. Indian Phytopathol. 71:279-283.

Maharachchikumbura, S. S. N., Guo, L. D., Cai, L., Chukeatirote, E., Wu, W. P., Sun, X., Crous, P. W., Jayarama Bhat, D., McKenzie, E. H. C., Bahkali, A. H., and Hyde, K. D. 2012. A multi-locus backbone tree for Pestalotiopsis, with a polyphasic characterization of 14 new species. Fungal Divers. 56:95-129.

Maharachchikumbura, S. S. N., Guo, L. D., Chukeatirote, E., Bahkali, A. H., and Hyde, K. D. 2011. Pestalotiopsis: morphology, phylogeny, biochemistry and diversity. Fungal Divers. 50:167-187.

Maharachchikumbura, S. S. N., Hyde, K. D., Groenewald, J. Z., and Crous, P. W. 2014. Pestalotiopsis revisited. Stud. Mycol. 79:121-186.

Mertely, J., Chamorro, M., and Peres, N. A. 2015. Pestalotiopsis spp., a newly discovered root pathogen of strawberry transplants. Phytopathology 105: S4.95.

Mertely, J., Marin, M., and Peres, N. A. 2019. Cultivar susceptibility to Pestalotiopsis spp., a developing pathogen of strawberry, 2018-19. Plant Dis. Manag. Rep. 13:PF066.

Mouden, N., Benkirane, R., Ouazzani Touhami, A., and Douira, A. 2014. Pathogenic capacity of Pestalotia longisetula Guba reported for the first time on strawberry (Fragaria ananassa Duch.) in Morocco. Int. J. Pure App. Biosci. 2:132-141. 
Obregón, V. G., Meneguzzi, N. G., Ibañez, J. M., Lattar, E., and Kirschbaum, D. S. 2018. First report of Neopestalotiopsis clavispora causing root and crown rot on strawberry plants in Argentina. Plant Dis. 102:1856.

Oliveira, M. S., Amiri, A., Zuniga, A. I., and Peres, N. A. 2017. Sources of primary inoculum of Botrytis cinerea and their impact on fungicide resistance development in commercial strawberry fields. Plant Dis. 101:1761-1768.

Pettitt, T. R., and Pegg, G. F. 1994. Sources of crown rot (Phytophthora cactorum) infection in strawberry and the effect of cold storage on susceptibility to the disease. Ann. Appl. Biol. 125:279-292.

Rambaut, A., and Drummond, A. 2012. FigTree: Tree Figure Drawing Tool, v1.4.2. Institute of Evolutionary Biology, University of Edinburgh, Edinburgh, Scotland.

Rebollar-Alviter, A., Silva-Rojas, H. V., Fuentes-Aragón, D., Acosta-González, U., Martínez-Ruiz, M., and Parra-Robles, B. E. 2020. An emerging strawberry fungal disease associated with root rot, crown rot and leaf spot caused by Neopestalotiopsis rosae in Mexico. Plant Dis. 104:2054-2059. https://apsjournals.apsnet.org/doi/10.1094/PDIS-11-19-2493-SC

Rehner, S. A. 2001. Primers for elongation factor 1-alpha (EF1-alpha). Available at: https://web.archive.org/web/20080514151555/http://ocid.nacse.org/research/ deephyphae/EF1primer.pdf

Rodrigues, F. A., Silva, I. T., Cruz, M. F. A., and Carré-Missio, V. 2014. The infection process of Pestalotiopsis longisetula leaf spot on strawberry leaves. J. Phytopathol. 162:690-692.

Ronquist, F., Teslenko, M., van der Mark, P., Ayres, D. L., Darling, A., Höhna, S., Larget, B., Liu, L., Suchard, M. A., and Huelsenbeck, J. P. 2012. MrBayes 3.2: efficient Bayesian phylogenetic inference and model choice across a large model space. Syst. Biol. 61:539-542.

Steyaert, R. L. 1949. Contributions à l'étude monographique de Pestalotia de Not et Monochaetia Sacc. (Truncatella gen. nov. et Pestalotiopsis gen. nov.). Bull. Jardin Bot. Etat Brux. 19:285-354.

Steyaert, R. L. 1955. Pestalotia, Pestalotiopsis et Truncatella. Bull. Jardin Bot. Etat Brux. 25:191-199.

Swofford, D. L. 2003. PAUP*: Phylogenetic Analysis Using Parsimony and Other Methods, version 4. Sinauer Associates, Sunderland, MA.

Van Hemelrijck, W., Ceustermans, A., Van Campenhout, J., Lieten, P., and Bylemans, D. 2017. Crown rot in strawberry caused by Pestalotiopsis. Acta Hortic. 1156:781-786.

Whitaker, V. M., Boyd, N. S., Peres, N. A., Desaeger, J., Noling, J. W., and Lahiri, S. 2019. Strawberry production. Chapter 16 in: Vegetable Production Handbook of Florida, 2019-2020. Available at: http://edis.ifas.ufl.edu/ pdffiles/cv/cv29200.pdf

White, T. J., Bruns, T., Lee, S., and Taylor, J. 1990. Amplification and direct sequencing of fungal ribosomal RNA genes for phylogenetics. Pages 315-322 in: PCR Protocols: A Guide to Methods and Applications. Academic Press, San Diego, CA.

Xu, L., Kusakari, S., Hosomi, A., Toyoda, H., and Narukokorozashi, O. 1999 Postharvest disease of grape caused by Pestalotiopsis species. Ann. Phytopathol. Soc. Jpn. 65:305-311.

Zhao, J. N. 2016. Pestalotiopsis clavispora causing leaf spot on strawberry. Mycosystema 35:114-120. 